\title{
Differences in Type I interferon response in human lung epithelial cells infected by highly pathogenic H5N1 and low pathogenic H11N1 avian influenza viruses
}

\author{
Milind M. Thube ${ }^{1} \cdot$ Pratip Shil $^{2} \cdot$ Rewati Kasbe $^{1} \cdot$ Avinash A. Patil $^{2} \cdot$ Shailesh D. Pawar $^{1} \cdot$ Jayati Mullick $^{1}$
}

Received: 2 March 2017 / Accepted: 16 March 2018 / Published online: 24 March 2018

(c) Springer Science+Business Media, LLC, part of Springer Nature 2018

\begin{abstract}
Influenza A virus infection induces type I interferons (IFNs $\alpha / \beta$ ) which activate host antiviral responses through a cascade of IFN signaling events. Herein, we compared highly pathogenic H5N1 and low pathogenic H11N1 avian influenza viruses isolated from India, for their replication kinetics and ability to induce IFN- $\beta$ and interferon-stimulating genes (ISGs). The $\mathrm{H} 5 \mathrm{~N} 1$ virus showed a higher replication rate and induced less IFN- $\beta$ and ISGs compared to the H11N1 virus when grown in the human lung epithelial A549 cells, reflecting the generation of differential innate immune responses during infection by these viruses. The non-structural 1 (NS1) protein, a major IFN-antagonist, known to help the virus in evading host innate immune response was compared from both the strains using bioinformatics tools. Analyses revealed differences in the composition of the NS1 proteins from the two strains that may have an impact on the modulation of the innate immune response. Intriguingly, H5N1 virus attenuated IFN- $\beta$ response in a non-NS1 manner, suggesting the possible involvement of other viral proteins (PB2, PA, PB1/PB1-F2) of H5N1 in synergy with NS1. Preliminary analyses of the above proteins of the two strains by sequence comparison show differences in charged residues. The insight gained will be useful in designing experimental studies to elucidate a probable role of the polymerase protein(s) in association with NS1 in inhibiting the IFN signaling and understanding the molecular mechanism governing the difference.
\end{abstract}

Keywords Influenza A Avian influenza $\cdot \mathrm{H} 5 \mathrm{~N} 1 \cdot \mathrm{H} 11 \mathrm{~N} 1 \cdot$ Interferon $\cdot$ NS1 Innate immune response $\cdot$ CPSF30

Edited by William Dundon.

This work was done in partial fulfillment of the Ph.D. thesis of M.M.T. submitted to the S. P. Pune University, Pune, India.

Electronic supplementary material The online version of this article (https://doi.org/10.1007/s11262-018-1556-1) contains supplementary material, which is available to authorized users.

Jayati Mullick

jayati_mullick@hotmail.com; mullick.j@niv.co.in

1 Avian Influenza Group, Microbial Containment Complex, ICMR-National Institute of Virology, 130/1 Sus Road, Pashan, Pune 411021, India

2 Bioinformatics Laboratory, Microbial Containment Complex, ICMR-National Institute of Virology, 130/1 Sus Road, Pashan, Pune 411021, India

\section{Introduction}

Influenza A viruses (IAV) of the family Orthomyxoviridae are zoonotic pathogens which pose a serious threat to human health globally. Because of their ability to reassort, they adapt to new hosts ensuring the generation of newer strains with varied degrees of pathogenicity and transmissibility [1,2]. Avian influenza (AI) viruses cause infections in poultry, and wild and migratory birds with sporadic birdto-human transmission [3-5]. Aquatic birds are the natural reservoirs [6] and to date all the AI subtypes have been isolated from them, except for the new bat-origin $\mathrm{H} 17 \mathrm{~N} 10$ and H18N11 [2]. AI viruses are classified as highly pathogenic avian influenza (HPAI) and low pathogenic avian influenza (LPAI) viruses. LPAI viruses are believed to be the genesis of HPAI viruses [3, 7]. Since the detection and isolation of HPAI-H5N1 from China in 1996 [8], the virus has spread in Asia causing outbreaks in poultry and human zoonotic infections [4,9]. India has witnessed several outbreaks of the HPAI-H5N1 strain in domestic poultry since 2006 
[10-12], which has prompted AI surveillance studies at the animal-human interface to understand the role of birds in the transmission of AI viruses.

The host innate immune responses serve as the first line of defense during viral infection restricting viral replication and spread. Type I interferons (IFNs) represented by IFN$\alpha / \beta$ are secreted as host antiviral responses during IAV infection sensed by Retinoic acid-like receptor (RLR) genes and expression of the IFN-stimulated genes (ISGs) through the JAK-STAT signaling pathway [13-15]. Non-structural protein-1 (NS1) acts as a principal IFN- $\beta$ antagonist by interfering with IFN production $[14,16]$ and IAVs lacking the NS1 gene can replicate in an IFN-deficient system [17], suggesting that HPAI strains may express NS1 that suppresses the host IFN-mediated antiviral effects. This premise set a platform to study differences in the host IFN-mediated responses elicited towards HPAI and LPAI viruses.

In the present study, we selected two unique AI strains, HPAI-H5N1 and LPAI-H11N1, that differ in their genetic organization and pathogenicity $[11,18,19]$, to study the host-mediated IFN responses and their modulation in human lung epithelial A549 cells. The HPAI-H5N1 virus isolated from the Manipur outbreak in 2007 was unrelated to the earlier H5N1 viruses in India [11]. The chosen LPAI-H11N1 virus was a reassortant isolated for the first time in India from a wild aquatic bird, with internal genes (NP, M) having $100 \%$ amino acid identity with the H5N1 virus [18]. Moreover, a microarray-based study reported that the H11N1-NS1 has the potential to modulate host-cellular environment [20]. Thus, we compared the replication kinetics of these viruses, gene-expression profile of IFN- $\beta$ and ISGs, and the ability of the respective NS1 to inhibit the IFN- $\beta$ responses. Using bioinformatics tools (sequence alignment and 3D structure prediction), we also compared the NS1 proteins.

\section{Materials and methods}

\section{Viruses and cells}

The viruses used in this study were isolated from India, namely A/Ck/India/NIV9743/07 (H5N1) [11] and A/Aquaticbird/India/NIV-17095/2007 (H11N1) [18]. The preparation of the virus stocks, hemagglutination (HA) assay was essentially as described earlier [21]. The HA titer for both the viruses was 512 HA units. The human lung epithelial A549 cell line used for all infection studies was maintained in Dulbecco's modified Eagle medium (DMEM; Invitrogen Life Technologies, USA) with $10 \%$ fetal bovine serum (FBS, Invitrogen), $100 \mathrm{U} / \mathrm{ml}$ penicillin, and $100 \mu \mathrm{g} / \mathrm{ml}$ streptomycin. Madin-Darby Canine Kidney (MDCK) cells were obtained from the American Type Culture Collection
(ATCC), USA, and used for determining the plaque-forming unit (pfu) by the standard plaque assays as a measure of the infectious virus titer of the stock as well as the infected cells for growth kinetic studies. MDCK cells were maintained in DMEM supplemented with $10 \% \mathrm{FBS}, 100 \mathrm{U} / \mathrm{ml}$ penicillin, and $100 \mu \mathrm{g} / \mathrm{ml}$ streptomycin in tissue culture flasks at $37^{\circ} \mathrm{C}$ in $5 \% \mathrm{CO}_{2}$.

\section{Plaque assay}

Madin-Darby Canine Kidney (MDCK) cells were seeded at a cell density of $0.7 \times 10^{6}$ cells per well in a six-well tissue culture plate (Nunc, Denmark) and grown at $37{ }^{\circ} \mathrm{C}$ in a $\mathrm{CO}_{2}$ incubator. After the cells attained confluency, the confluent monolayers were washed with DMEM medium without FBS and infected with serial virus dilutions $\left(10^{-1}\right.$ till $\left.10^{-5}\right)$ and incubated for $1 \mathrm{~h}$ at $37^{\circ} \mathrm{C}$. After the incubation period, the cells were overlaid with overlay media containing $0.18 \%$ SeaKem LE Agarose (Lonza, Switzerland) and allowed to solidify. After $48 \mathrm{~h}$ of incubation at $37^{\circ} \mathrm{C}$, the plaques were stained with $0.1 \%$ crystal violet and counted. The virus titer was calculated as plaque-forming unit per milliliter (PFU/ $\mathrm{ml})$.

\section{Viral replication experiments}

Growth kinetics of both the viruses (H5N1 and H11N1) was monitored in A549 cells and the titers determined by plaque assay in MDCK cells. In brief, A549 cells $\left(1.5 \times 10^{5}\right.$ cells $)$ were infected at a multiplicity of infection (MOI) of 0.01 with the viruses independently and incubated for the desired time. The medium for H11N1 virus contained $2 \mu \mathrm{g} / \mathrm{ml}$ Tosyl phenylalanyl chloromethyl ketone (TPCK) trypsin. Supernatants were collected at various time points of incubation such as $2,12,24,48$, and $72 \mathrm{~h}$. The viral titer of the infected supernatants of all the above time points was measured by determining the pfus by the standard plaque assay in MDCK cells. The experiment was conducted thrice independently. Infection experiments with HPAI-H5N1 virus were conducted in a Biosafety level 3 (BSL3) laboratory.

\section{Real-time PCR experiments}

Innate immune response to these viruses and the $\mathrm{M}$ gene content was studied by quantitative gene-expression profiling using Real-time RT-PCR. In brief, A549 cells were infected with the respective viruses at MOI 4. RNA was isolated from the infected cells at $12 \mathrm{~h}$ post-infection (hpi) using the RNeasy mini kit (Qiagen, Germany). DNA traces were removed by DNase I (Promega, USA) treatment. The respective RNAs along with controls (636 ng) were subjected to 
Table 1 List of primers used for real-time RT-PCR

\begin{tabular}{|c|c|c|c|}
\hline S. no. & Primer name & Primer sequence & References \\
\hline 1 & Isg 15 forward & 5'-TCCTggTgAggAATAACAAggg-3' & [15] \\
\hline 2 & Isg 15 reverse & 5'-CTCAgCCAgAACAggTCgTC-3' & [15] \\
\hline 3 & IFITM forward & 5'-CAAggAggAgCACgAgg-3' & {$[35]$} \\
\hline 4 & IFITM reverse & 5'-TTgAACAgggACCAgACg-3' & {$[35]$} \\
\hline 5 & RIG I forward & 5'-gCAgAggCCggCATgAC-3' & {$[34]$} \\
\hline 6 & RIG I reverse & 5'-TgTAggTAgggTCCAgggTCTTC-3' & {$[34]$} \\
\hline 7 & MDA5 forward & 5'-TggTCgAgCCAgAgCTgAT-3' & {$[34]$} \\
\hline 8 & MDA5 reverse & 5'-ACTCCTgAACCACTgTgAgCAA-3' & {$[34]$} \\
\hline 9 & MX1 forward & 5'-TCCAgCCACCATTCCAAggAg-3' & {$[15]$} \\
\hline 10 & MX1 reverse & 5'-CTTggAATggTggCTggATg-3' & [15] \\
\hline 11 & IFN- $\beta$ forward & 5'-ATgACCAACAAgTgTCTCCTCC-3' & {$[36]$} \\
\hline 12 & IFN- $\beta$ reverse & 5'-gCTCATggAAAgAgCTgTAgTg-3' & {$[36]$} \\
\hline 13 & PKR forward & 5'-gCCTTTTCATCCAAATggAATTC-3' & [15] \\
\hline 14 & PKR reverse & 5'-gAAATCTgTTCTgggCTCATg-3' & [15] \\
\hline 15 & 18S rRNA forward & 5'-gCTTAATTTgACTCAACACgggA-3' & {$[15]$} \\
\hline 16 & 18S rRNA reverse & 5'-AgCTATCAATCTgTCAATCCTgTC-3' & {$[15]$} \\
\hline 17 & M gene forward & 5'-GACCRATCCTGTCACCTCTGAC-3' & {$[37]$} \\
\hline 18 & M gene reverse & 5'-AGGGCATTYTGGACAAAKCGTCTA-3' & [37] \\
\hline
\end{tabular}

cDNA preparation using High-Capacity cDNA Reverse Transcription Kit (ABI, USA). Innate immune response genes and the $M$ gene content were quantitated by SYBR green real-time RT-PCR (ABI) in ABI 7500 fast real-time PCR system and normalized to the levels of $18 \mathrm{~S} \mathrm{mRNA}$. The PCR conditions were as follows: $95{ }^{\circ} \mathrm{C}$ for $10 \mathrm{~min}$ followed by 40 cycles of $94^{\circ} \mathrm{C}$ for $15 \mathrm{~s}, 55^{\circ} \mathrm{C}$ for $60 \mathrm{~s}$, and $72{ }^{\circ} \mathrm{C}$ for $60 \mathrm{~s}$. Primer sequences of the target genes are listed in Table 1 . The data are presented as relative mRNA expression fold induction and are representative of two experiments of three independent replicates. The relative expression levels of the target genes were analyzed by the comparative $\Delta \Delta C_{\mathrm{t}}$ method [22].

\section{Luciferase assays}

NS1 genes from the H11N1 and H5N1 viruses were amplified by RT-PCR and cloned into the mammalian expression vector pCDNA3.1 (Invitrogen). The reporter plasmid expressing the firefly luciferase under the control of IFN- $\beta$ promoter (pGL4-IFN-Luc) was generated by cloning the human IFN- $\beta$ promoter amplified from human lymphocyte RNA by RT-PCR into pGL4 (Promega) vector upstream of the luciferase gene. Transient transfection was performed in subconfluent A549 cells in 12-well cell culture plates. In brief, $500 \mathrm{ng}$ of pGL4-IFN- $\beta$-Luc reporter plasmid, 2 or $3 \mu \mathrm{g}$ of either pCDNA-H11N1-NS1 or pCDNA-H5N1-NS1 expression plasmid, and $5 \mathrm{ng}$ of Renilla luciferase plasmid as an internal control for normalization of transfection efficiency were mixed with Lipofectamine 2000 transfection reagent (Invitrogen) and incubated for $20 \mathrm{~min}$ at room temperature (RT) before adding to the cells. Sixteen hours post-transfection, cells were induced by adding $500 \mathrm{ng}$ of PolyI:C (InvivoGen, USA) as extracellular stimulation. Cells were analyzed for reporter activation $40 \mathrm{~h}$ post-transfection by measuring the firefly luciferase activity and the Renilla luciferase activity using the Dual-Glo Luciferase Assay System (Promega), according to the manufacturer's protocol. The luminescence was read by a VICTOR X3 Multilabel Plate Reader (Perkin Elmer). Respective controls such as mock (lacking NS1 plasmid and PolyI:C) and a positive control (PC; lacking only NS1 expression plasmid) were used for comparison.

\section{Quantitation of IFN- $\beta$ by ELISA}

A549 cells were infected with the H5N1 and H11N1 viruses at MOI 4 in a 6-well cell culture plate. Mock-infected cells received an equal amount of phosphate-buffered saline (PBS), pH 7.4. Cells were incubated at $37^{\circ} \mathrm{C}$ for $24 \mathrm{~h}$ in a $\mathrm{CO}_{2}$ incubator. After $24 \mathrm{hpi}, 100 \mu \mathrm{l}$ of supernatant from the mock-infected as well as the virus-infected cells were added to a 96-well plate for determination of IFN- $\beta$ concentration. ELISA was performed along with the standards according to the manufacturer's protocol (PBL Assay Science, USA). The absorbance was measured at $450 \mathrm{~nm}$. The amount of IFN- $\beta$ was estimated from the standard curve. Statistical significance was determined by the Student's $t$ test. 


\section{Western blot and quantitation}

A549 cells were infected with the $\mathrm{H} 11 \mathrm{~N} 1$ and $\mathrm{H} 5 \mathrm{~N} 1$ viruses at MOI 4. Total cellular protein from the infected cells was extracted using cell lysis buffer (1\% NP40) $24 \mathrm{~h}$ postinfection. Protein content of the cell lysates was determined using the Bradford reagent (Biorad, USA). Equal amount of protein $(25 \mu \mathrm{g})$ was separated on $12 \%$ SDS-PAGE and transferred to PVDF membrane (Amersham Bioscience, USA) at $100 \mathrm{~V}$ for $1 \mathrm{~h}$. After blocking, the membrane was probed with a monoclonal anti-NS1 antibody (Santa Cruz Biotechnology, USA). For Western blots, the proteins were visualized by chemiluminescence using the ECL detection system (Amersham Bioscience). The blot was stripped and re-probed with anti $\beta$-actin antibody (Santa Cruz Biotechnology) as the loading control. For quantification of the protein content, scanned images of the Western blot were analyzed by densitometry using ImageJ (Image Processing and Analysis in Java, National Institute of Health, USA) software.

\section{Bioinformatics analyses}

In order to understand the differences between the NS1 proteins from the two strains at the molecular level, sequence analyses and structural comparison were carried out using bioinformatics tools. The amino acid sequences of NS1 protein from the $\mathrm{H} 5 \mathrm{~N} 1$ and $\mathrm{H} 11 \mathrm{~N} 1$ viruses were aligned using FASTA software (https://fasta.bioch.virginia.edu/). The 3D structures for these sequences were predicted by an homology-based modeling protocol as implemented in the SWISS-MODEL online server (https://swissmodel.expas y.org/) with the automated mode. The predicted structures were evaluated using PROCHECK analysis (http://www. ebi.ac.uk/thorntonsrv/software/PROCHECK). Minimized energy for the structures was calculated using GROMOS96 force-field in SwissPDBViewer (SPDBV) [23]. Visualization of the structures was carried out using Discovery Studio Viewer 4.1. Surface electrostatic analysis for the structures was carried out in NOC software v3.01 [24].

\section{Statistical analysis}

The Student's $t$ test was applied for the replication kinetics, comparison of the $\mathrm{M}$ gene content and the innate immune response genes, luciferase assays, and IFN- $\beta$ content.

\section{Results and discussion}

\section{Growth kinetics of HPAI-H5N1 and LPAI-H11N1 strains}

To ascertain viable virus production, first we compared the growth kinetics of the HPAI and LPAI viruses-A/Ck/ India/NIV9743/07 (H5N1) [11] and A/Aquaticbird/India/ NIV-17095/2007 (H11N1) [18] in the human lung A549 cells. Virus stock preparation and hemagglutination (HA) assay were performed as described earlier [21]. The infectious virus titer of both the viruses was estimated by determining the pfu by the standard plaque assay. A549 cells were infected with the LPAI and HPAI viruses at equal multiplicity of infection (MOI) 0.01 and the infectious virus titers (pfu) were analyzed as a function of time by the standard plaque assay. Both the isolates replicated well in A549 cells. The virus titers between the two isolates differed significantly $(P<0.01)$ over time after $12 \mathrm{~h}$ until $24 \mathrm{~h}$, and remained as a plateau until $72 \mathrm{~h}$ (Fig. 1a). It is also clear from the figure that the difference in the infectious virus titer between these isolates remained the same until $48 \mathrm{hpi}$. These data suggest that there is no difference in the early stages of infection between the viruses; however after $12 \mathrm{hpi}$, the higher replication rate of $\mathrm{H} 5 \mathrm{~N} 1$ compared to H11N1 virus results in higher titers. Further insight regarding the replication potential of the viruses was confirmed by an immunofluorescence assay using the anti-NP antibody (Fig. S1). The figure clearly shows an increased number of NP-expressed cells in both the HPAI and LPAI viruses at the two time points.

\section{Gene-expression profile of innate immune response genes}

Next, we sought to determine whether the above difference in the replication rate is due to the viruses' ability to initiate type I IFN responses in A549-infected cells (MOI 4), by studying gene-expression profiling of the innate immune response and pattern-recognition receptor genes, and the $M$ gene content (Table 1) using quantitative SYBR green realtime RT-PCR. The M gene content (Fig. 1b) was found to be consistent with the replication pattern of the respective viruses (Fig. 1a). We observed that the expression of IFN- $\beta$ and RLR genes (RIG-1 and MDA-5) was significantly higher $(P<0.05)$ in the H11N1 virus-infected cells compared to the $\mathrm{H} 5 \mathrm{~N} 1$ virus (Fig. 1c-e). There was a marginal increase in RIG-1 expression and significantly higher $(P<0.01)$ expression of MDA-5 in the H11N1 virus-infected cells. Among the ISG's analyzed in this study, expression of ISG-15 was marginally increased, whereas the expression of IFITM, MX1, and PKR genes was significantly $(P<0.05)$ higher in 
(a)

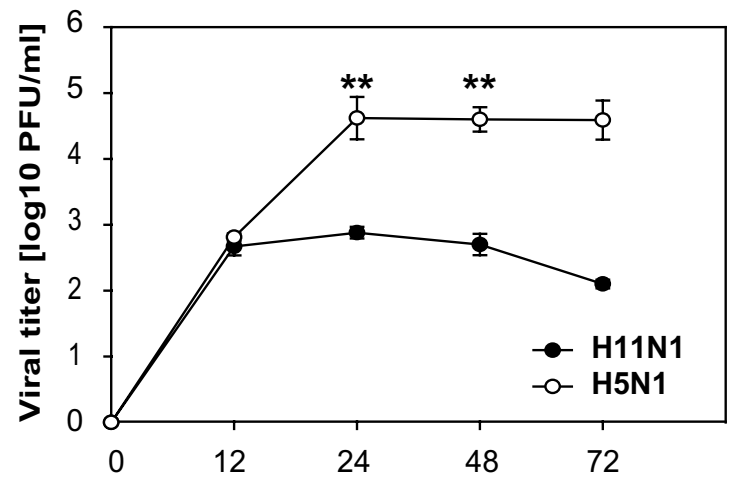

Time (Hours post-infection)

(b)

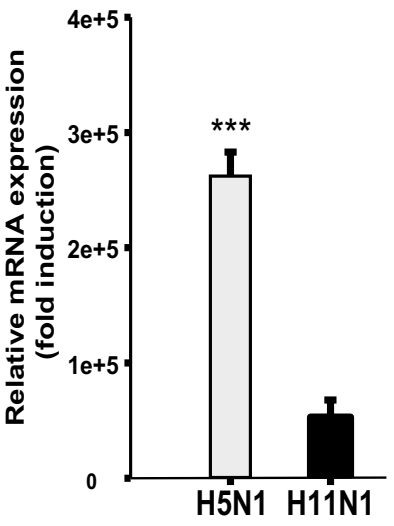

(f)

ISG-15

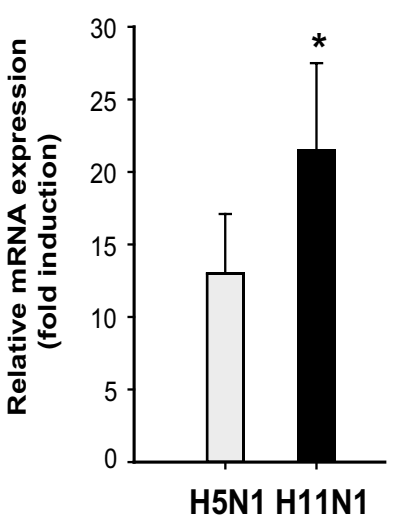

(c)

IFN $\beta$

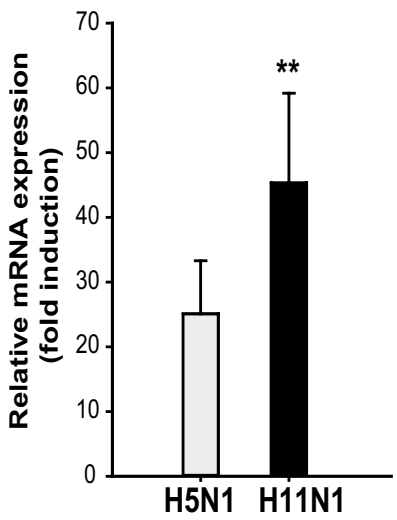

(g)

IFITM

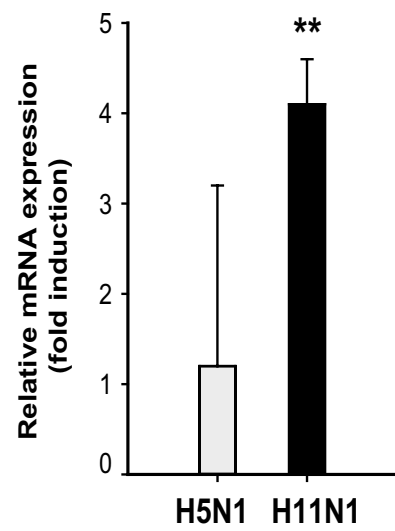

(d)

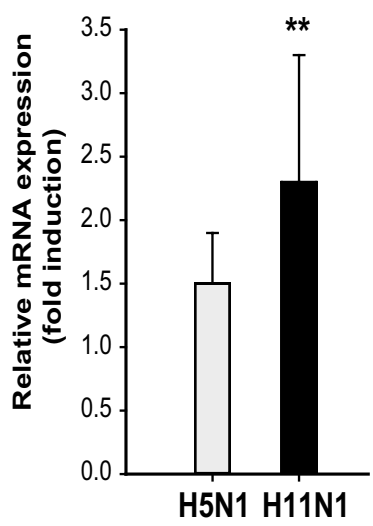

(h)

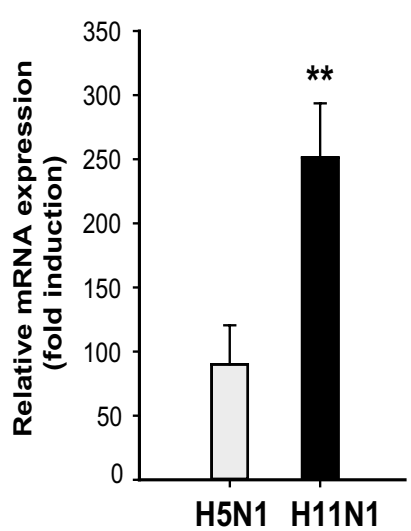

(e)

MDA-5

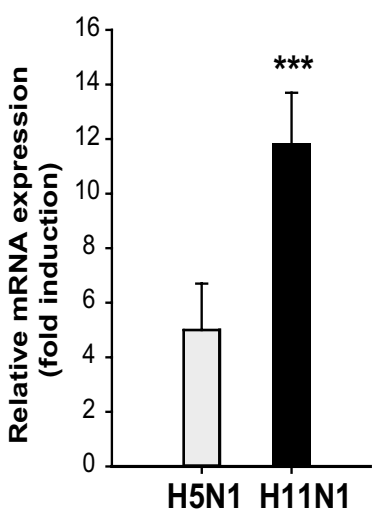

(i)

PKR

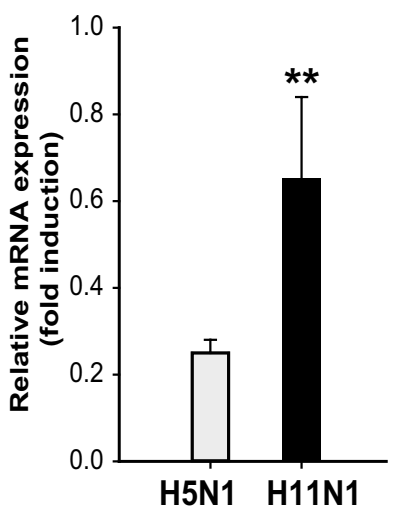

Fig. 1 Replication kinetics of the H11N1 and H5N1 viruses in A549 cells and differential expression of innate immune response genes. a The viral titer of the infected supernatants of A549 cells at timepoints $(2,12,24,48$, and $72 \mathrm{~h})$ was determined by plaque assay in MDCK cells. The graphs represent mean \pm SEM of three independent experiments. Asterisks indicate the statistical significance between H11N1 and $\mathrm{H} 5 \mathrm{~N} 1$ viruses $(* * P<0.01$; Student's $t$ test). b M gene expres-

sion in $\mathrm{H} 11 \mathrm{~N} 1$ and $\mathrm{H} 5 \mathrm{~N} 1$ virus-infected A549 cells and $\mathbf{c}-\mathbf{i}$ Innate immune response against $\mathrm{H} 11 \mathrm{~N} 1$ and $\mathrm{H} 5 \mathrm{~N} 1$ in A549 cells by quantitative SYBR green real-time RT-PCR. Results were analyzed by the comparative $\Delta \Delta C_{\mathrm{t}}$ method. Asterisks indicate the statistical significance between mRNA expressions of the $\mathrm{H} 5 \mathrm{~N} 1$ and $\mathrm{H} 11 \mathrm{~N} 1$ viruses by Student's $t$ test $(* P<0.1 ; * * P<0.05 ; * * * P<0.01)$ 


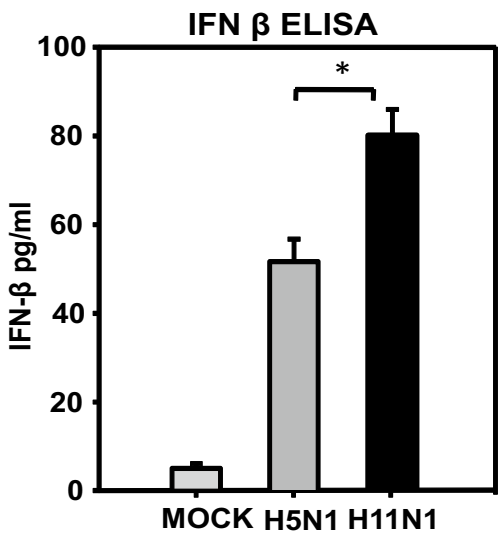

Fig. 2 Quantitation of IFN- $\beta$ from H5N1 virus- and H11N1 virusinfected cells by ELISA. A549 cells were either infected with the $\mathrm{H} 5 \mathrm{~N} 1$ and $\mathrm{H} 11 \mathrm{~N} 1$ viruses at MOI 4 or mock-infected and incubated at $37{ }^{\circ} \mathrm{C}$ for $24 \mathrm{~h}$. IFN- $\beta$ concentration in the cell supernatants was determined by ELISA after $24 \mathrm{~h}$. Asterisk indicates statistical significance by the Student's $t$ test $\left({ }^{*} P<0.05\right)$

the H11N1 virus-infected cells than the H5N1 virus-infected cells (Fig. 1f-i). These results clearly indicate an increased amount of the intracellular RNA sensors in the LPAI virusinfected cells that probably enhance the expression of host IFN- $\beta$ and ISG's. Consistent with the elevated level of the IFN- $\beta$ gene, higher amounts of IFN- $\beta$ was expressed by the LPAI-H11N1 compared to the HPAI-H5N1 virus as determined by ELISA (Fig. 2). Similar studies with HPAI-H5N1 and the prototypic seasonal H3N2 strain suggest that differential IFN activation depends on the RIG-1 gene [25].

\section{Effect of NS1 on IFN- $\beta$ expression}

Subsequently, we asked whether the lower expression of IFN- $\beta$ during H5N1-virus infection compared to H11N1virus infection was due to the inhibitory action of NS1 on the production of IFN- $\beta$, by comparing the capacity of transiently expressed NS1 of the respective strains for inhibiting the IFN- $\beta$ promoter in A549 cells using the Luciferase reporter assay system. Normalization of the transfection efficiency was achieved by cotransfecting the Renilla luciferase plasmid as an internal control. Results displayed in Fig. 3a show that the positive control which has PolyI:C but lacks the NS1 plasmid strongly drives the IFN- $\beta$ promoter activation of the luciferase gene. Though the transfected cells showed equal expression of both NS1 proteins (Fig. 3b), importantly, the H11N1-NS1 influenced a greater level of inhibition $(P<0.05)$ of the IFN- $\beta$ promoter activation compared to that of the H5N1-NS1 (Figs. 3a, S2). These results were further corroborated by immunoblotting the infected cell extracts with the anti-NS1 antibody which showed higher NS1 expression in H11N1-infected cells (Fig. 3c). The fact that the H11N1 virus-infected A549 cells produce greater amounts of NS1 protein relative to the H5N1 virus appears to contradict the replication kinetics shown in Fig. 1a. While it is acknowledged that greater protein expression levels do not necessarily result in higher infectious titers, differential regulation of translation of viral proteins for the LPAI and HPAI viruses might be a plausible explanation for the differences. It, however, is likely that the increased inhibition of IFN- $\beta$ mRNA expression by H5N1 in comparison to H11N1 may be driven by an entity in synergy with NS1. The role of other gene segments is supported by an earlier study [4] and recent studies wherein viral polymerase proteins PB2, PA, and PB1-F2 affect virulence by inhibiting IFN- $\beta$ expression [25-29]. A preliminary sequence comparison analysis of the above proteins of H5N1 and H11N1 showed differences in charged residues (Fig. 4a-c), suggestive of a possible role of H5N1 polymerases along with NS1 in modulating IFN signaling that needs to be addressed separately.

\section{Sequence and structure comparison of H5N1- and H11N1-NS1 proteins}

Studies on the effect of different NS genes and single amino acid mutations from LPAI viruses on viral pathogenicity led to the identification of new residues in the NS gene important for mammalian pathogenicity [30]. Thus, in our study the significant differences observed in the ability of NS1 of the LPAI and HPAI viruses to inhibit IFN- $\beta$-prompted analysis of amino acid variations in NS1 and its structural comparison using bioinformatics tools. Results of pairwise alignment of H5N1 and H11N1 showed 13 amino acid variations and a 5 amino acid (80-84) deletion in H5N1 (Fig. 3d). The NS1 protein binds to the $30-\mathrm{kDa}$ subunit of the cleavage and polyadenylation-specificity factor (CPSF30) to regulate cellular mRNA processing leading to general inhibition of the host antiviral response [16]. Notably, we found N171D (H5N1 vs H11N1) within the CPSF30 binding site (144-188) while M111V and T112A in close vicinity of another CPSF30 binding site (103-106), thus we propose that these changes might affect the binding of NS1 to CPSF30 in the H11N1 virus, thus modulating the host antiviral response. The role of the 5 amino acid residues (80-84) in IFN signaling is less plausible, as a study showed that deletion of these residues enhanced the virulence of H5N1 viruses [31], and these residues are not present in LPAI viruses, including the H11N1 virus in this study. In addition, the residues are not located within the CPSF30 binding sites of H11N1-NS1.

A 3D structure prediction of the NS1 proteins was obtained using the crystallographic structure of Influenza/A H6N6 NS1 (4OPH.PDB) as template using methods described earlier [23, 24]. The target template sequence identity was $93.33 \%$ for $\mathrm{H} 5 \mathrm{~N} 1$ and $98.70 \%$ for 
(a)

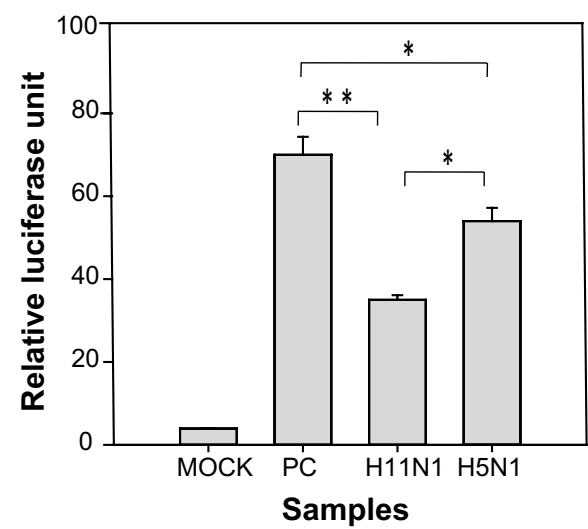

(b)

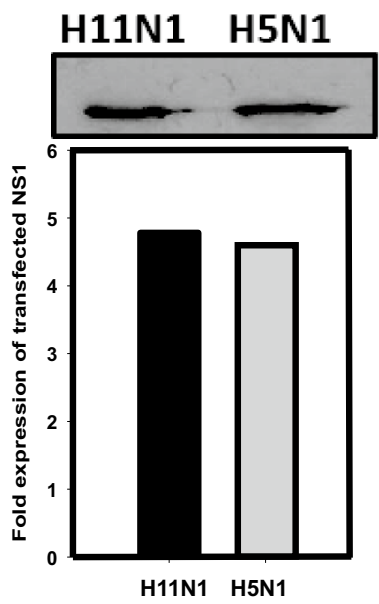

(c)

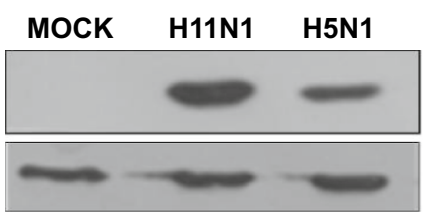

NS1

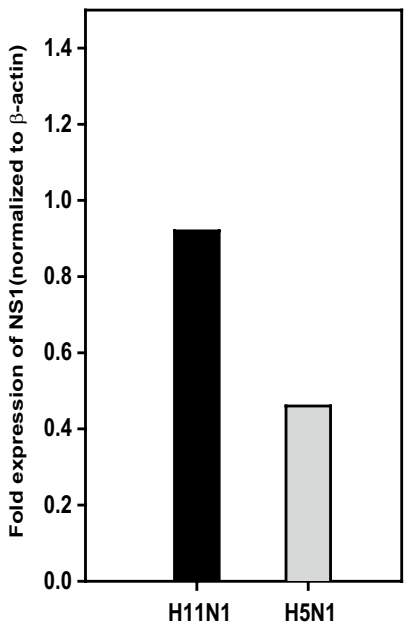

$\beta$-actin

(d)

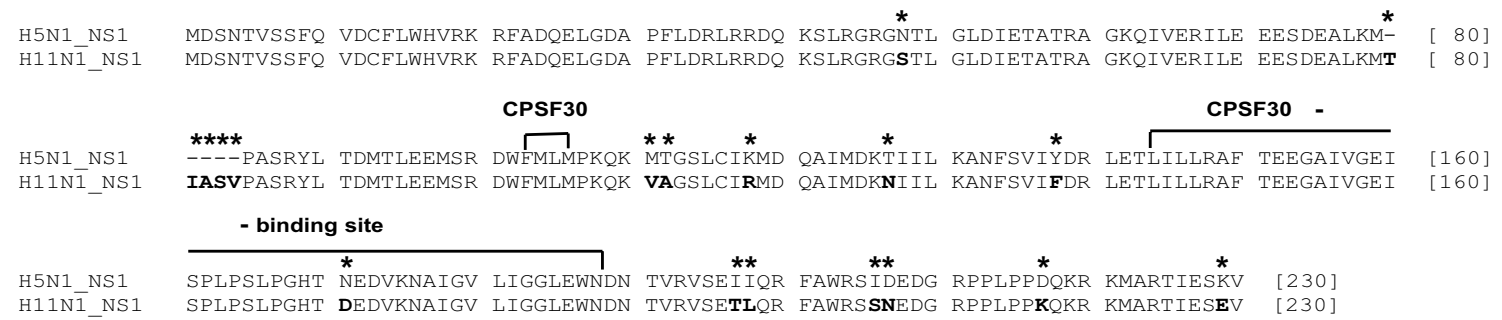

Fig. 3 Ability of NS1 to inhibit IFN- $\beta$, expression of NS1 in infected cells, and pairwise alignment of NS1 proteins of H5N1 and H11N1 viruses. a Luciferase activities of A549 cells cotransfected with a luciferase reporter plasmid under the control of IFN- $\beta$ promoter pGL4-IFN- $\beta$-luc and internal control (Renilla plasmid) followed by induction with PolyI:C. Data are presented as relative luciferase units \pm SEM of three independent experiments. Asterisks indicate statistical significance by the Student's $t$ test $(* P<0.05 ; * * P<0.01)$. b Total cellular protein $(25 \mu \mathrm{g})$ from the H11N1 and H5N1-NS1transfected A549 cells and c cell lysate (equal protein) from A549 cells infected with H11N1 and H5N1 virus, were separated by SDSPAGE and immunoblotted with anti-NS1 antibody. The graph in

H11N1. The minimized energy of NS1 from H5N1 and H11N1 was -9967.9 and $-10,103 \mathrm{~kJ} / \mathrm{mol}$, respectively. b represents fold expression of the transfected NS1 as quantified by densitometry analysis. The blot in $\mathbf{c}$ was stripped and re-probed with anti- $\beta$-actin antibody. The NS1 protein band signal intensity was normalized to the signal intensity of the respective $\beta$-actin and plotted as a graph. d NS1 protein sequences of $\mathrm{H} 5 \mathrm{~N} 1$ and $\mathrm{H} 11 \mathrm{~N} 1$ viruses were aligned and the different domains identified. Residues from 1-73 and 74-230 represent the RNA binding domain and the effector domain of the NS1 proteins, respectively. Residues highlighted in bold font and indicated with asterisk represent differences between $\mathrm{H} 5 \mathrm{~N} 1$ and H11N1-NS1. The 5 amino acid deletion in H5N1 NS1 is from residues 80-84. The CPSF30 binding sites at residues 103-106 and 144188 have been shown by black horizontal lines

Superimposition of the 3D structures indicated a root-meansquared deviation of $0.22 \AA$ involving 760 backbone atoms, 
(a) H5N1_PA H11N]_PA

H5N1 PA. H11N] 1 PA

H5N1 PA H11N1_PA

H5N1 PA H11N]1_PA

H5N1 PA H11N]_PA

H5N1 PA H11N]1_PA

H5N1_PA H11N 1 - PA

H5N1 PA H11N 1 PA

H5N1_PA H11N1 PA

(b) H5N1 PB1 H11N1﹎.PB1

H5N1 PB1 H11N1_PB1

H5N1 PB1 H11N̄ 1 PB1

H5N1 PB1 H11N1 1 PB1

H5N1 PB1 H11N1 PB1

H5N1 PB1 H11N̄ $\mathrm{PB} 1$

H5N1_PB1 H11N1 $\mathrm{PB} 1$

H5N1 PB1 ต11N1_PB1

H5N1 PB1 H11Nำ_PB1

H5N1 PB1 H11N1 1 PB1
MEDFVRQCFNENIVEILAEKAMKEYGEDPKIETNKFAAICTHLEVCEMYSDFHFIDERSESIIVESGDPNAIIJKHRFEIIE MEDFVRQCFNPMIVELAEKAMKEYGEDPKIETNKFAAICTHLEVCEMYSDFHFIDERGESI IVESGDPNALIKHRFEI IE

GRDRTAAWTVVNSICNTTGVEKPKFLPDLYDYKENRFIEIGVTRREVHTYYLEKANKIKSEKTHIHIFSFTGEEMATKAD GRDRTMAWTIVNSICNTTGVDKPKFLPDLYDYKENRFIEIGVTRREVHIYYLEKANKIKSEKTHIHIFSFTGEEMATKAD

YTLDEESRARTKTRIFTIRQENASRGLWDSFRQSERGEETIEEKFEITGTMRIIADQSLPPNFSSIENFRAYVDGFEPNG YTLDEESRARIKTRLFTIRQENASRGLWDSFRQSERGEETIEERFEITGTHRILADQSLPPNFSSIENERAYVDGFEPNG

CIEGKLSQMSKEVNARIEPFLKTTPRPLRLPDGPPCSQRSKFIIMIDALKLSIEDPSHEGEGIPLYTATKCYKTFFGKKEP CIEGKLSQ ASKEVNARIEPFLKTTPRPLKLPDGPPCSQRSKFIIMDALKLSIEDPSHEGEGIPLYTAIKCXKTFFGWKEP

NIVKPHEKGINLNYILLTWKQVLAELQDIENGEKIPKTKNMIKKTSQLKWALGENMAPEKVDFEDCKDVSDLRQYDSEEPES NIIKPHEKGINPNYILAKKQVLAELQDIENEEKIPKTKNIKKTSQLKTALGENHAPEKVDFEDCKDVSDLRQYDSDEPES

RSLASWIQSEFNKACELTDSSWIELDEIGEDVAPIEHIASARRNYFTAEVSHCRATEYTMKGVYINTAI.INASCAAMDDF RSLASWIQSEFNKACELTDSSWIELDEIGEDVAPIEHIASMRR WYFTAEVSHCRATEYTMIKGVYIMTALLNASCAAMDDF

QLIFAISKCRTKEGRRKTNLYGFIIKGRSHIRNDTDVVNFVSMEFSLTDPRLEPHKWEKYCVLEIGDWILRTAVGQVSRP QLIPMISKCRTKEGRRKTNLYGFIIKGRSHIRNDTDVVNFVSMIEFSLTDPRLEPHKWEKYCVLEIGDAIILRTAIGQVSRP

MFLYYRTNGTSKIKAIKWGMARRCI.LQSLQQIESHIESESSVKEKTATKKEFEENKSEAWPIGESPKGVEEGSIGKVCRTL MFLYVRTNGTSKIKAIKWEAMARRCIIQSLQQIESAIEAESSVKEKDWTKDFFENKSETWPIGESPKGVEEGSIGKVCRTL.

LAKSVFNSLYASS $\stackrel{*}{*}$ QLEGFSAESRKLULLÄQALRDNLEPGT FDLGGLYEATEECLINDPWVLLNASWFNSFLAHALK LAKSVFNSLYASPQLEGFSAESRKT.I.LIVQALRDNLEPGTFDLGGLYEATEECLINDPWVI.NASWFNSFLTHAIK

MDVNPTLILFLKVPVQNAISTTFPYTGDPPYSHGTGTGYTHITVNRTHQYSEKGKWTTNTVTTGAPQLNPIDGPLPEDNEPS MDVNPTLLFLKVPAQNAISTTFPYTGDPPYSHGTGTGYTMTVNRTHQYSEKGKTTTNTETGAPQLNPIDGPLPEDNEPS

GYAQTDCVLEAMAFLEESHPGIFENSCLETMEIVQQTRVDKLTQGRQTYTWTLNRNQPAATSLANTIEIFRSNGLTANES GYAQTDCVIEAMAFLEESHPGI FENSCIETKEVVQQTRVDKLTQGRQTYDWTLNRNQPAATAIANTIEVFRSNGLTANES

GRLIDFLKDVMESHDKEEMEITTHFQRKRRVRDNHTRKAVTQRTIGKKKQRLNKKSYLIRALTLNTMTKDAERGKIKRRA GRLIDFLKDVMESHDKEEAEITTHFQRKRRVRDNHTKKMVTQRTIGKKKQRLNKRSYLIRALTLNTRTKDAERGKIKRRA

IATPGHQIRGFVYFVETLARSICEKLEQSGLPVGGNEKKAKLANVVRKMNTNSQDTELSFTITGDNTKWNENQNPRIFLA IATPGQIRGFVYFVETLARSICEKIEQSGLPVGGNEKKAKI.ANVVRKARTNSQDTELSFTITGDNTKWNENQNPFAFTAA

MITYITRNQPEWFRNULSIAPTHFSNKMARLGRGYMFESKSHKTITTQIPAFAI_ANIDLKYFNELTKKKIEKIRPIIIDET MITYITRNQPEWFRNVLSIAPTMFSNKMARLGKGYMFESKSIIKLRTQIPAEIYIANIDLKYFNESTRKKIEKIRPLIIDGT

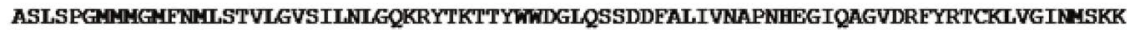
ASLSPGIMAGYNILSTVLGVSILNLGQKRYTKTTYWWDGLSSDDFALIVNAPNHEGIQAGVDRFYRTCKLVGINMSKK

KSYINRTGTEEFTSFFYRYGEVANFSMELPSFGVSGINESADNSIGVTVIKNINHINNDLGPATAQAALQLFIKDYRYTYR KSYINRTGTFEFTSFFYRYGEVANFSNELPSFGVSGINESADWSIGVTVIKNINMTNNDLGPATAQMALQLETKDYRYTYR

CHRGDTQIQTRRSFELKKLWEQTRSKAGLLVSDGGPNLYNIRNLHIPEVCLKKEINDEDYQGRLCNPLNPFVSHKEIESV CHRGDTQIQTRRSEELKKLWEQTRSKAGLLVSDGGPNLYNIRNIHIPEVCLKWEINDEDYQGRLCNPLNPFVSHKEIESV

NNAVVIPAHGPAKSMIEYDAVATTHSWI PKRNRSIINTSQRGILEDEQYYQKCCNLFEKFFPSSSYRRPVGISSAVEARVS NNAVVIPAHGPAKSAIEYDAVATTHSWI PKRNRSIINTSQRGILEDEQMYQKCCSLFEKFFPSSSYRRPVGISSAVEAMVS

RARIDARIDFESGRIKEEEFAEIIRICSTIEELRRPKRARIDARIDFESGRIKTEEFAETMKICSTIEELRRQK

Fig. 4 Pairwise alignment of PA, PB1, and PB2 proteins of H5N1 and H11N1 viruses. PA (a), PB1 (b), and PB2 (c) protein sequences of H5N1 and $\mathrm{H} 11 \mathrm{~N} 1$ viruses were aligned. Differences in charged residues between H5N1 and H11N1 are indicated by asterisk 
(c)

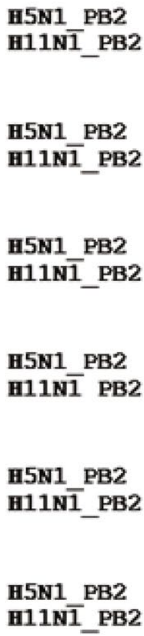

SSFSFGGFTFKRTSGSSVTKEEEVLTGNLQTLKIRVHEGYEEFTMIG G\%RATAILRKATRRLIQLIVSGRDEQSIAEAIIV SSFSFGGFTFKRTSGSSVKREEEVLTGNLQTLKIRVHEGYEEFTMVGRRATAIIRKATRRLIQLIVSGRDEQSIAFAIIV

AMVFSQEDCAMKAVRGDI.NFVNRANQRT.NENHQIIRHFQKTAKVLFQNWGIEPIDNVMGMTGILPTWTPSTEMSI.RGVRV

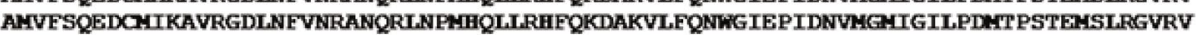

SKTGVDEYSSTERIVUSIDRFLRVRDQRGNVLLSPEEVSETQGTEKLTITYSSSAIWEINGPESVLVNTYQWIIRMTETV SKMGVDEYSSTERVVVSIDRFLRVRDQRGNVLLSPEEVSETQGTEKLTITYSSSWIWEINGPESVLVNTYQWIIRNWETV

KIQWSQDPTKLYNKAEFEPFQSLVPKAARGQYSGFVRTLFQCNRDVLGTFDTVQIIKLLPFAAAPPKQSRMQFSSLTVNV KIQWSQDPTILYNKAEFEPFQSLVPKAARGQYSGFVRTLFQQMRDVLGTFDTVQIIKULPFAAAPPEQSFAQFSSLTVNV

FGSGRILIRGNSPVENYNKATKRLTVLGKDAGALTEDPDEGTAGVESAVLRGFLILGKEDKRYGPALSINELSNLAKGE RGSGARILVRGNSPVFWYNKATKRLTVLGKDAGALTEDPDEGTAGVESAVLRGFLILGKEDKRYGPALSINELSNIAKGE

\section{KANVLIGQGDVVLVWKRKRDSSTLTDSQTATKRIRMATN}

KANVLIGQGDVVLVHIRKRDSSILTDSQTATKRIRMAIN

Fig. 4 (continued)

implying that the proteins have high structural similarity in terms of backbone fold. However, the above amino acid differences created local modifications in the surface contour and surface electrostatics (Fig. S3). The most prominent was N171D (H5N1 vs H11N1) which altered the local electrostatics around the CPSF30 binding site, wherein the H11N1-NS1 becomes more positively charged. The position of residue 171 in the backbone of the NS1 proteins is indicated in the ribbon mode display (Fig. S3). Since the specificity of protein-protein interaction depends on shape, complementarity of surface-contours of the participating proteins, surface electrostatics, and capacity to form $\mathrm{H}$-bonds or chemical interaction, any change and resulting alteration of local surface contour and/or surface electrostatics affects protein-protein binding. Scrutiny of H11N1-NS1 sequences from GenBank and H5N1 strains (2006-2011) revealed N171 in the majority of H5N1 viruses and D171 in all $\mathrm{H} 11 \mathrm{~N} 1$ viruses. The presence of charged aspartic acid residue in $\mathrm{H} 11 \mathrm{~N} 1$ may modulate the binding affinity for CPSF30 to NS1. The inability of the NS1 protein of the 2009 pandemic influenza H1N1 virus to block host gene expression in human and swine cells has been attributed to reduced binding efficiency of NS1 to CPSF30 [32]. Hence, in our study, N171D and other differences between H5N1 and H11N1-NS1 and polymerase proteins may be responsible for the altered functional efficiency reflected by the differential response in inhibition of IFN- $\beta$ promoter activation.

In conclusion, our study suggests that between the LPAI and HPAI viruses, the HPAI-H5N1 effectively attenuates IFN responses as a possible strategy to evade the host innate immune assault by a viral entity in synergy with NS1. However, which one among the IFN-antagonists (PB2, PA, or $\mathrm{PB} 1)$ is responsible needs to be investigated. Though there are comparative studies between $\mathrm{H} 5 \mathrm{~N} 1$ and the human seasonal viruses $\mathrm{H} 1 \mathrm{~N} 1$ and $\mathrm{H} 3 \mathrm{~N} 2$ [25, 33], this study on LPAI and HPAI viruses adds significant data for mammalian pathogenicity studies on AI viruses. In the wake of emerging AI viruses and differential interferon responses to HPAI and LPAI viruses, the insight gained will be useful in designing further structural and protein interaction studies targeted at NS1 and polymerases for understanding host-virus interactions and molecular mechanisms governing differences in IFN responses.

Acknowledgements We thank Ajit Rattan, Sachin Keng, Dinesh Singh, JPN Babu, SK Waghmare, AB Khare, and BSL3 staff for laboratory assistance, and P Aher, Drs. K Lole, P Yadav, and P Devhare for their help. We acknowledge the constant support of Dr. AC Mishra (ExDirector) and Dr. DT Mourya, Director, NIV. We are grateful to Dr. Cecilia Dayaraj and Dr. Sarah Cherian for their critical comments. The work was supported by intramural funds from the Indian Council of Medical Research, New Delhi, India, and financial assistance to M. Thube from the Council of Scientific and Industrial Research, New Delhi, India and R. Kasbe from the University Grants Commission, New Delhi, India is gratefully acknowledged.

Author contributions Conceived the idea and initiated the work: MMT \& JM. Contributed to design of experiments: MMT, SDP, PS, \& JM. Performed the experiments: MMT, RK, \& PS (Bioinformatics). Contributed reagents/materials/analysis tools: JM, SDP, \& PS. Analysis of experiments and results: MMT, PS, \& JM. Contribution in generating graphics: MMT, RK, \& AAP. Writing of the manuscript: MMT, PS, \& JM. All the authors read and approved the manuscript.

\section{Compliance with ethical standards}

Conflict of interest The authors declare that they have no conflict of interest.

Research involving human participants and/or animals This research work does not involve human participants and/or animals. 
Informed consent Not applicable as no human participants are involved.

\section{References}

1. P. Palese, M.L. Shaw, in Fields of Virology, ed. by D.M. Knipe, P.M. Howley (Lippincott Williams and Wilkins, Philadelphia, 2007), p. 1647

2. G. Neumann, Y. Kawaoka, Virology 479-480, 234-246 (2015)

3. D.L. Suarez, in Avian Influenza, 1st edn., ed. by D.E. Swayne (Blackwell, Iowa, 2008), p. 3

4. J.S. Peiris, M.D. de Jong, Y. Guan, Clin. Microbiol. Rev. 20, 243-267 (2007)

5. Z.M. Zhao, K.F. Shortridge, M. Garcia, Y. Guan, X.F. Wan, J. Gen. Virol. 89, 2182-2193 (2008)

6. R.G. Webster, W.J. Bean, O.T. Gorman, T.M. Chambers, Y. Kawaoka, Microbiol. Rev. 56, 152-179 (1992)

7. Y. Xu, A.M. Ramey, A.S. Bowman, T.J. DeLiberto, M.L. Killian, S. Krauss, J.M. Nolting, M.K. Torchetti, A.B. Reeves, R.J. Webby, D.E. Stallknecht, X.F. Wan, J. Virol. 91, e02208-e02216 (2017)

8. X. Xu, K. Subbarao, N.J. Cox, Y. Guo, Virology 261, 15-19 (1999)

9. M.L. Perdue, in Avian Influenza, ed. by D.E. Swayne (Blackwell, Iowa, 2008), p. 23

10. K. Ray, V.A. Potdar, S.S. Cherian, S.D. Pawar, S.M. Jadhav, S.R. Waregaonkar, A.A. Joshi, A.C. Mishra, Virus Genes 36, 345-353 (2008)

11. A.C. Mishra, S.S. Cherian, A.K. Chakrabarti, S.D. Pawar, S.M. Jadhav, B. Pal, S. Raut, S. Koratkar, S.S. Kode, Virol. J. 6, 26-34 (2009)

12. A.K. Chakrabarti, S.D. Pawar, S.S. Cherian, S.S. Koratkar, S.M. Jadhav, B. Pal, S. Raut, V. Thite, S.S. Kode, S.S. Keng, B.J. Payyapilly, J. Mullick, A.C. Mishra, PLoS ONE 4, e7846 (2009)

13. B. Opitz, A. Rejaibi, B. Dauber, J. Eckhard, M. Vinzing, B. Schmeck, S. Hippenstiel, N. Suttorp, T. Wolff, Cell. Microbiol. 9, 930-938 (2007)

14. G.A. Versteeg, A. Garcia, in Viruses and Interferon Current Research, ed. by K. Mossman (Caister Academic Press, Norfolk, 2011), p. 181

15. D. Jia, R. Rahbar, R.W.Y. Chan, S.M.Y. Lee, M.C.W. Chan, B.X. Wang, D.P. Baker, B. Sun, J.S. Malik Peiris, J.M. Nicholls, E.N. Fish, PLoS ONE 5, e13927 (2010)
16. B.G. Hale, R.E. Randall, J. Ortín, D. Jackson, J. Gen. Virol. 89, 2359-2376 (2008)

17. A. García-Sastre, A. Egorov, D. Matassov, S. Brandt, D.E. Levy, J.E. Durbin, P. Palese, T. Muster, Virology 252, 324-330 (1998)

18. S. Pawar, A. Chakrabarti, S. Cherian, S. Pande, M. Nanaware, S. Raut, B. Pal, S. Jadhav, S. Kode, S. Koratkar, V. Thite, A. Mishra, Virus Genes 41, 14-22 (2010)

19. S.S. Koratkar, S.D. Pawar, V.N. Shelke, S.D. Kale, A.C. Mishra, Indian J. Med. Res. 139, 782-785 (2014)

20. S. Mukherjee, S. Majumdar, V.C. Vipat, A.C. Mishra, A.K. Chakrabarti, Virol. J. 9, 149-160 (2012)

21. D.S. Tare, S.D. Pawar, J. Virol. Methods 224, 67-72 (2015)

22. K.J. Livak, T.D. Schmittgen, Methods 25, 402-408 (2001)

23. P. Shil, S.S. Chavan, S.S. Cherian, Bioinformation 7, 76-81 (2011)

24. P. Shil, S. Chavan, S. Cherian, Bioinformation 6, 266-270 (2011)

25. M. Matthaei, M. Budt, T. Wolff, PLoS ONE 8, e56659 (2013)

26. Z.T. Varga, A. Grant, B. Manicassamy, P. Palese, J. Virol. 86, 8359-8366 (2012)

27. M.J. Killip, E. Fodor, R.E. Randall, Virus Res. 209, 11-22 (2015)

28. J.C.D. Long, E. Fodor, J. Virol. 90, 8729-8738 (2016)

29. G. Kochs, A. Garcia-Sastre, L. Martinez-Sobrido, J. Virol. 81, 7011-7021 (2007)

30. I.-H. Kim, H.-J. Kwon, S.-H. Lee, D.-Y. Kim, J.-H. Kim, Vet. Microbiol. 175, 17-25 (2015)

31. J.X. Long, D.X. Peng, Y.L. Liu, Y.T. Wu, X.F. Liu, Virus Genes 36, 471-478 (2008)

32. B.G. Hale, J. Steel, R.A. Medina, B. Manicassamy, J. Ye, D. Hickman, R. Hai, M. Schmolke, A.C. Lowen, D.R. Perez, A. GarciaSastre, J. Virol. 84, 6909-6922 (2010)

33. H. Zeng, C. Goldsmith, P. Thawatsupha, M. Chittaganpitch, S. Waicharoen, S. Zaki, T.M. Tumpey, J.M. Katz, J. Virol. 81, 12439-12449 (2007)

34. D. Goubau, R. Romieu-Mourez, M. Solis, E. Hernandez, T. Mesplède, R. Lin, D. Leaman, J. Hiscott, Eur. J. Immunol. 39, 527-540 (2009)

35. D. Li, Z. Peng, H. Tang, P. Wei, X. Kong, D. Yan, F. Huang, Q. Li, X. Le, Q. Li, K. Xie, Clin. Cancer Res. 17, 3558-3568 (2011)

36. P.B. Devhare, S.N. Chatterjee, V.A. Arankalle, K.S. Lole, PLoS ONE 8, e63793 (2013)

37. CDC protocol of realtime RTPCR for influenza A viruses, http:// www.who.int/csr/resources/publications/swineflu/realtimeptpcr/ en/ 